Supporting Information

\title{
Liquid-Core Capsules via Interfacial Polymerization: A Free-Radical Analogy of the Nylon Rope Trick
}

\author{
Charles Scott, Dan Wu, Chia-Chi Ho, and Carlos C. Co* \\ University of Cincinnati, Department of Chemical and Materials Engineering 497 Rhodes Hall, \\ Cincinnati, OH 45221 \\ *Corresponding author. E-mail: carlos.co@uc.edu
}

\section{Experimental Methods and Materials}

All reagents and anhydrous solvents were purchased from Sigma-Aldrich or Acros Organics/Fisher Scientific and used without further purification. Reactions were conducted in oven-dried glassware under an argon atmosphere. Proton $\left({ }^{1} \mathrm{H}\right)$ and carbon $\left({ }^{13} \mathrm{C}\right)$ nuclear magnetic resonance (NMR) spectra were recorded using a Bruker AC 250 spectrometer (250 MHz for ${ }^{1} \mathrm{H}$ NMR and $62.5 \mathrm{MHz}$ for ${ }^{13} \mathrm{C}$ NMR). Chemical shifts $(\delta)$ are measured in parts per million ( $\mathrm{ppm}$ ) of the spectrometer base frequency, and are referenced to the residual ${ }^{1} \mathrm{H}$ (methanol: $4.87 \mathrm{ppm}$, chloroform: 7.24 , water: $4.80 \mathrm{ppm}$ ) or ${ }^{13} \mathrm{C}$ (methanol: 49.15 ppm, chloroform: $77.00 \mathrm{ppm}$ ) solvent signal. Coupling constants $(J)$ are reported in Hertz $(\mathrm{Hz})$ for ${ }^{1} \mathrm{H}$ NMR spectra; ${ }^{13} \mathrm{C}$ NMR spectra were recorded using broadband ${ }^{1} \mathrm{H}$ decoupling. High resolution mass spectra (HRMS) were obtained on a Micromass Q-TOF II spectrometer, using electrospray ionization, from the University of Cincinnati Mass Spectrometry Facility. The exact mass is reported for the molecular ion $\left(\mathrm{M}^{+}\right)$as $\mathrm{M} / \mathrm{e}$. Melting points (mp) were determined on a Mel-Temp II melting point apparatus and are uncorrected. Electronic absorption (UV) spectra were recorded on a Cary 50 Bio UV-Vis spectrometer. Absorption maxima $\left(\lambda_{\max }\right)$ are reported in nanometres 
$(\mathrm{nm})$, with the molar extinction coefficients $(\varepsilon)$ reported in parentheses in units of $\mathrm{M}^{-1} \mathrm{~cm}^{-1}$. Infrared spectra were recorded on a Perkin Elmer Spectrum One infrared spectrometer. Liquid samples were analyzed neat as thin films between two sodium chloride plates. Solid samples (1 mg) were ground with IR grade $\mathrm{KBr}(100 \mathrm{mg})$ in an agate mortar and pressed into a disc $(1 \mathrm{~cm})$ using an Econo Press (Thermo 0026-001). The position of selected absorption maxima $\left(v_{\max }\right)$ are reported in units of $\mathrm{cm}^{-1}$.

Dibutyl maleate (1). Dibutyl maleate (1) was purchased from Acros Organics and used without further purification.

2-[Vinyloxypoly(oxyethylene)]ethylene (2). 2-[Vinyloxypoly(oxyethylene)]ethylene

(2) was prepared using a procedure analogous to that used in the preparation of methoxypoly(oxyethylene) vinyl ether by Sedaghat-Herati et al. ${ }^{1} \quad$ Poly(ethylene glycol) (PEG) $\left(20 \mathrm{~g}, 20 \mathrm{mmol}, \mathrm{M}_{\mathrm{n}}=1000\right)$ was dissolved in dichloromethane $(100 \mathrm{~mL})$ with triethylamine $(8.34 \mathrm{~mL}, 6.05 \mathrm{~g}, 60 \mathrm{mmol})$ and cooled in an ice-bath. Following addition of methanesulfonyl chloride $(4.66 \mathrm{~mL}, 6.70 \mathrm{~g}, 60 \mathrm{mmol})$, the solution was stirred for 20 hours before filtering to remove the precipitated triethylammonium chloride. Dimesylated PEG was precipitated from the filtrate through addition of diethyl ether (150 $\mathrm{mL}$ ), isolated by filtration, and dried to yield an off-white solid (23 g, $20 \mathrm{mmol}, 99 \%$ yield). ${ }^{1} \mathrm{H} \mathrm{NMR}\left(\mathrm{CDCl}_{3}, 250 \mathrm{MHz}\right) \delta 3.01(\mathrm{~s}, 6 \mathrm{H}), 3.62(\mathrm{br} \mathrm{s}, 88 \mathrm{H}), 3.74(\mathrm{t}, J=5 \mathrm{~Hz}$, 4H), $4.36(\mathrm{t}, J=5 \mathrm{~Hz}, 4 \mathrm{H})$. Ethylene glycol vinyl ether $(4.40 \mathrm{~mL}, 4.32 \mathrm{~g}, 49 \mathrm{mmol})$ was added to a suspension of sodium hydride $(1.6 \mathrm{~g}, 40 \mathrm{mmol})$ in THF $(100 \mathrm{~mL})$ and stirred for 1 hour. Mesylated PEG (23 g, $20 \mathrm{mmol})$ was then added and stirred at room temperature for 24 hours. Following removal of the solvent by rotary evaporation, the residue was dissolved in methylene chloride $(100 \mathrm{~mL})$, washed with water $(5 \times 10 \mathrm{~mL})$, and dried by azeotropic distillation with toluene. Precipitation from ether at $0^{\circ} \mathrm{C}$ followed by filtration and drying yielded $2\left(12 \mathrm{~g}, 11 \mathrm{mmol}, 53 \%\right.$ yield) as an off-white solid. ${ }^{1} \mathrm{H}$ 
NMR $\left(\mathrm{CDCl}_{3}, 250 \mathrm{MHz}\right) \delta 3.62(\mathrm{br} \mathrm{s}, 96 \mathrm{H}), 3.71(\mathrm{~m}, 4 \mathrm{H}), 3.82(\mathrm{~m}, 4 \mathrm{H}), 3.98(\mathrm{dd}, J=2$, $6.5 \mathrm{~Hz}, 2 \mathrm{H}), 4.16$ (dd, $J=2,14.5 \mathrm{~Hz}, 2 \mathrm{H}), 6.47$ (dd, $J=6.5,14.5 \mathrm{~Hz}, 1 \mathrm{H})$.

\section{2,2'-azobis(N-octyl-2-methyl-propionamidine) dihydrochloride (3). 2,2'-azobis(1-} imino-1-methoxy-2-methylpropane) hydrochloride was prepared using modifications on the synthesis described by Bizilj et al. ${ }^{2}$ Azobisisobutyronitrile (AIBN) (2.62 g, $16 \mathrm{mmol}$ ) was dissolved in toluene $(150 \mathrm{~mL})$ with methanol $(3.0 \mathrm{~mL}, 2.37 \mathrm{~g}, 74 \mathrm{mmol})$. After cooling to $0.5^{\circ} \mathrm{C}, \mathrm{HCl}$ gas was bubbled through the solution for a period of 6 hours, then sealed and stirred overnight. The resulting white precipitate was isolated by filtration and washed with toluene to give 2,2'-azobis(1-imino-1-methoxy-2-methylpropane) hydrochloride (4.80 g, $16 \mathrm{mmol}, 95 \%$ yield). ${ }^{1} \mathrm{H}$ NMR $\left(\mathrm{D}_{2} \mathrm{O}, 250 \mathrm{MHz}\right) \delta 1.49(\mathrm{~s}, 12 \mathrm{H})$, 3.77 (s, 6H). 2,2'-azobis(1-imino-1-methoxy-2-methylpropane) hydrochloride (2.02 g, 7 mmol) was suspended in methanol $(10 \mathrm{~mL})$ and octylamine $(2.30 \mathrm{~mL}, 1.80 \mathrm{~g}, 14 \mathrm{mmol})$ was added dropwise. Solvent removal by rotary evaporation leaves a pale orange solid, that after re-crystallization from methanol/ethyl acetate yields 3 (2.55 g, $5 \mathrm{mmol}, 77 \%$ yield) as a white powder. $\mathrm{mp}=132-4{ }^{\circ} \mathrm{C}(\mathrm{dec}) ;{ }^{1} \mathrm{H} \mathrm{NMR}\left(\mathrm{CD}_{3} \mathrm{OD}, 250 \mathrm{MHz}\right) \delta 0.92(\mathrm{t}$, $J=6.5 \mathrm{~Hz}, 6 \mathrm{H}), 1.34(\mathrm{~m}, 12 \mathrm{H}), 1.39(\mathrm{~m}, 8 \mathrm{H}), 1.63(\mathrm{~s}, 12 \mathrm{H}), 1.77(\mathrm{~m}, 4 \mathrm{H}), 3.53(\mathrm{t}, J=7$ $\mathrm{Hz}, 4 \mathrm{H}) ;{ }^{13} \mathrm{C}$ NMR $\left(\mathrm{CD}_{3} \mathrm{OD}, 62.5 \mathrm{MHz}\right) \delta 14.7,23.8,24.0,24.1,27.9,28.8,30.4,33.0$, 44.0, 74.0, 170.5; IR (KBr) 3207, 3030, 2928, 2857, 1699, 1682, 1628, 1527, 1465, 1373, 1337, 1203, 1191, 828, $736 \mathrm{~cm}^{-1}$; UV/Vis (methanol, $\left.2.46 \times 10^{-4} \mathrm{M}\right) 210$ (8650), 370 (26) $\mathrm{nm}\left(\mathrm{M}^{-1} \mathrm{~cm}^{-1}\right)$; HRMS (ESI, +) Calcd for $\mathrm{C}_{24} \mathrm{H}_{51} \mathrm{~N}_{6}(\mathrm{M}-2 \mathrm{HCl}+1)$ : 423.4175. Found: 423.4196 .

Decomposition rates for azo-initiator 3 were determined at $50,55,60,65$, and $70{ }^{\circ} \mathrm{C}$ by measuring the decrease in UV absorption of the azo bond (366 nm) over time. Quartz UV cuvettes, containing a known concentration of the initiator in isobutanol $\left(1.68 \times 10^{-2}\right.$ $\left.\mathrm{M}, \lambda_{\max }=366 \mathrm{~nm}\left(\varepsilon=24 \mathrm{M}^{-1} \mathrm{~cm}^{-1}\right)\right)$, were thermostated in a water bath $\left( \pm 0.02^{\circ} \mathrm{C}\right)$ and 
removed at regular intervals to measure the UV absorption. Decomposition kinetics: 10hour half-life $=59.5^{\circ} \mathrm{C}, \mathrm{E}_{\mathrm{a}}=133 \mathrm{kJmol}^{-1}, \ln \mathrm{A}=37.1, \mathrm{k}_{60^{\circ} \mathrm{C}}=1.8 \times 10^{-5} \mathrm{~s}^{-1}$.

$N$-ethyl- $N, N$-dimethyl-2-(vinyloxy)ethylammonium chloride (4). Chloroethyl vinyl ether $(10.0 \mathrm{~mL}, 10.45 \mathrm{~g}, 98 \mathrm{mmol})$ and $N, N$-dimethylethylamine $(15.0 \mathrm{~mL}, 10.13 \mathrm{~g}, 138$ $\mathrm{mmol})$ in methanol $(100 \mathrm{~mL})$ was sealed in a thick-wall reaction vessel and heated to 125 ${ }^{\circ} \mathrm{C}$ (45 psi) for 3 days. Removal of the solvent and excess amine by rotary evaporation gave the desired product (17.47 g, $97 \mathrm{mmol}, 99 \%$ yield) as a viscous light brown oil. ${ }^{1} \mathrm{H}$ NMR $\left(\mathrm{CD}_{3} \mathrm{OD}, 250 \mathrm{MHz}\right) \delta 1.42(\mathrm{t}, J=7 \mathrm{~Hz}, 3 \mathrm{H}), 3.18(\mathrm{~s}, 6 \mathrm{H}), 3.54(\mathrm{q}, J=7 \mathrm{~Hz}), 3.74$ $(\mathrm{m}, 2 \mathrm{H}), 4.20(\mathrm{~m}, 3 \mathrm{H}), 4.39(\mathrm{dd}, J=14.5,2 \mathrm{~Hz}, 1 \mathrm{H}), 6.55(\mathrm{dd}, J=14.5,7 \mathrm{~Hz}, 1 \mathrm{H}) ;{ }^{13} \mathrm{C}$ $\operatorname{NMR}\left(\mathrm{CD}_{3} \mathrm{OD}, 62.5 \mathrm{MHz}\right) \delta 8.9,51.8,62.2,63.0,63.4,89.4,151.9$; IR (neat) 3012, 2982, 2956, 1638, 1625, 1484, 1469, 1324, 1196, 1137, 1091, 1014, 976, 919, 829, 728 $\mathrm{cm}^{-1}$; HRMS (ESI, +) Calcd for $\mathrm{C}_{16} \mathrm{H}_{36} \mathrm{O}_{2} \mathrm{~N}_{2} \mathrm{Cl}(2 \mathrm{M}-\mathrm{Cl})$ : 323.2465. Found: 323.2454.

Interfacial Miniemulsion Polymerizations. Miniemulsions (60 g) were prepared by homogenizing oil and aqueous phases, containing the monomers, hydrophobe (osmotic balancing agent to suppress Ostwald ripening), and surfactant, with an homogenizer (IKA-Works T25 Ultra-Turrax) for 5 minutes followed by 3 minutes of horn sonication (278 W, $2.5 \mathrm{~s}$ pulses separated by $1 \mathrm{~s}$ intervals, Ace Glass Autotune Series 750W sonicator). Miniemulsions were then transferred to an absolute heat flow reaction calorimeter (CPA 200, ChemiSens AB). Reactions were initiated thermally at $60^{\circ} \mathrm{C}$ via injection of an aqueous solution of $3(0.32 \mathrm{~g}, 0.77 \mathrm{mmol}$ in $2.0 \mathrm{~mL}$ water $)$ through a 1.12 $\mathrm{mL}$ injection loop, or photochemically at $35^{\circ} \mathrm{C}$ via irradiation at $365 \mathrm{~nm}$ with a $150 \mathrm{~W}$ UV lamp (B1B-150P, Spectronics Corp.). Kinetic data was collected for 18 (thermal) or 40 (photochemical) hours and the extent of vinyl ether conversion was calculated from the vinyl ether/dibutyl maleate copolymerization enthalpy of $61.1 \mathrm{~kJ} / \mathrm{mol}$. This enthalpy 
of copolymerization was calorimetrically measured from solution polymerizations of equimolar mixtures of ethylene glycol vinyl ether and dibutyl maleate in toluene whose final conversion can be gravimetrically verified.

Thermal Polymerization of dibutyl maleate (1) with divinyl PEG 2. Oil phase: 1 $(1.55 \mathrm{~g}, 6.8 \mathrm{mmol}), 5 \%$ paraffin wax $\left(\mathrm{mp}=54-6^{\circ} \mathrm{C}\right)$ in hexadecane $(4.46 \mathrm{~g})$. Aqueous phase: 2 (3.45 g, $3.0 \mathrm{mmol})$, DTAB (0.51 g, $1.6 \mathrm{mmol})$ and water $(50.1 \mathrm{~g})$.

Polymerization of dibutyl maleate (1) with divinyl PEG 2 and cationic vinyl ether 4. Oil phase: 1 (1.54 g, $6.7 \mathrm{mmol}), 5 \%$ paraffin wax $\left(\mathrm{mp}=54-6^{\circ} \mathrm{C}\right)$ in hexadecane $(4.45 \mathrm{~g})$. Aqueous phase: 2 (3.11 g, $2.7 \mathrm{mmol}), 4(0.12 \mathrm{~g}, 0.67 \mathrm{mmol})$, DTAB (0.51 g, $1.6 \mathrm{mmol})$ and water $(50.1 \mathrm{~g})$.

\section{Thermal Polymerization of dibutyl maleate (1) with divinyl PEG 2 (half loading).}

Oil phase: $1(0.78 \mathrm{~g}, 3.4 \mathrm{mmol}), 5 \%$ paraffin wax $\left(\mathrm{mp}=54-6^{\circ} \mathrm{C}\right)$ in hexadecane $(5.2 \mathrm{~g})$. Aqueous phase: 2 (1.73 g, $1.5 \mathrm{mmol})$, DTAB (0.52 g, $1.7 \mathrm{mmol})$ and water $(52.2 \mathrm{~g})$.

Photochemical polymerization of dibutyl maleate (1) with divinyl PEG 2. Oil phase: $1(1.55 \mathrm{~g}, 6.8 \mathrm{mmol}), 5 \%$ paraffin wax $\left(\mathrm{mp}=54-6^{\circ} \mathrm{C}\right)$ in hexadecane $(4.46 \mathrm{~g})$. Aqueous phase: 2 (3.75 g, $3.3 \mathrm{mmol})$, DTAB (1.0424 g, $3.4 \mathrm{mmol})$, azo-initiator 3 (0.43 g, 0.86 $\mathrm{mmol})$ and water (104.06 g).

Dynamic Light Scattering (DLS). Capsules prepared by interfacial polymerization of miniemulsions were diluted one hundred fold with aqueous DTAB solutions $\left(1.56 \times 10^{-2}\right.$ $\mathrm{M}-\mathrm{CMC}$ concentration) to minimize interactions and multiple scattering without destabilizing the capsules. DLS measurements were performed using a Brookhaven Instruments Corporation ZetaPALS instrument at a fixed scattering angle of $90^{\circ}$ and wavelength of $662 \mathrm{~nm}$. Number-weighted size distributions were calculated from the 
intensity autocorrelation using the packaged particle sizing (multimodal size distribution, Ver3.4) MSD algorithm. See Figures S1 through S4 below.

Transmission Electron Microscopy. Imaging was conducted on a JEOL JEM-1230 transmission electron microscope fitted with an AMT Advantage Plus $2 \mathrm{~K}$ x 2K digital camera. One drop of the sample solution was placed on a copper grid coated with 100mesh Formvar (Electron Microscopy Sciences). The drop was blotted gently with filter paper to a thin film spanning the grid, frozen in hexane $\left(-80^{\circ} \mathrm{C}\right)$, then air dry at room temperature prior to imaging; no contrast agents were applied. See Figures S5-S7 for additional TEM images not included in the main text.

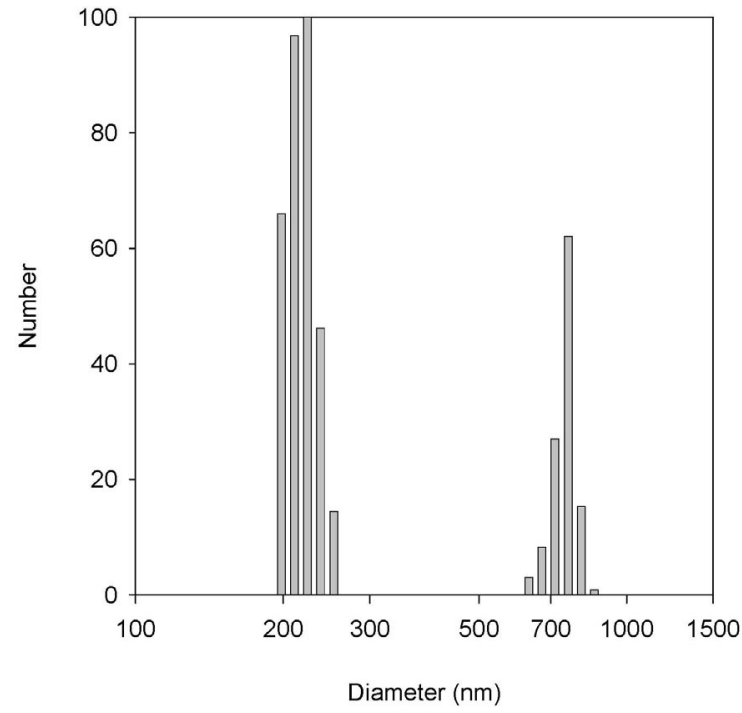

Figure S1. DLS analysis from thermal polymerization of dibutyl maleate (1) with divinyl PEG 2 showing a bimodal distribution with average diameters of $218 \pm 15 \mathrm{~nm}(73 \%$ of total population) and $745 \pm 41 \mathrm{~nm}(27 \%)$. (Figure 1, circles).

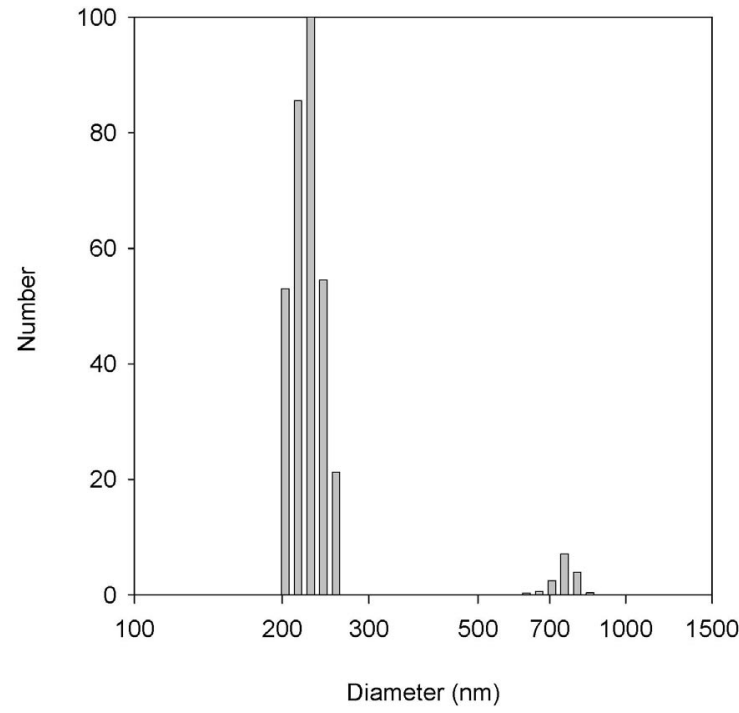

Figure S2. DLS analysis from thermal polymerization of dibutyl maleate (1) with 10 $\mathrm{wt} \%$ cationic monomer $\mathbf{4}$ and divinyl PEG 2 , showing a bimodal distribution with average diameters of $225 \pm 15 \mathrm{~nm}$ (95\% of total population) and $751 \pm 43 \mathrm{~nm}(5 \%)$. (Figure 1, squares). 


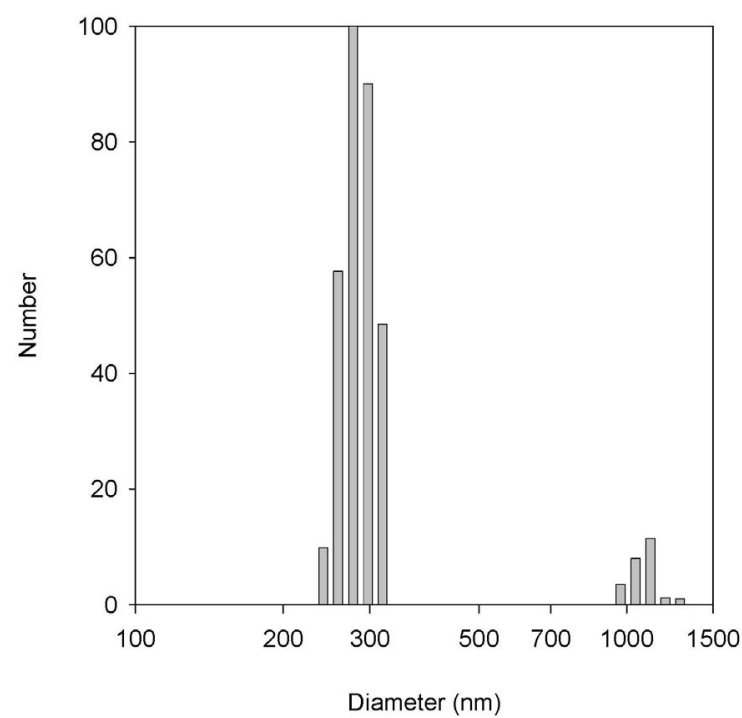

Figure S3. DLS analysis from thermal polymerization of dibutyl maleate (1) with divinyl PEG 2 with half monomer loading, showing a bimodal distribution with average diameters of $284 \pm 21 \mathrm{~nm}(92 \%$ of total population) and $1083 \pm 73 \mathrm{~nm}(8 \%)$. (Figure 1, triangles).

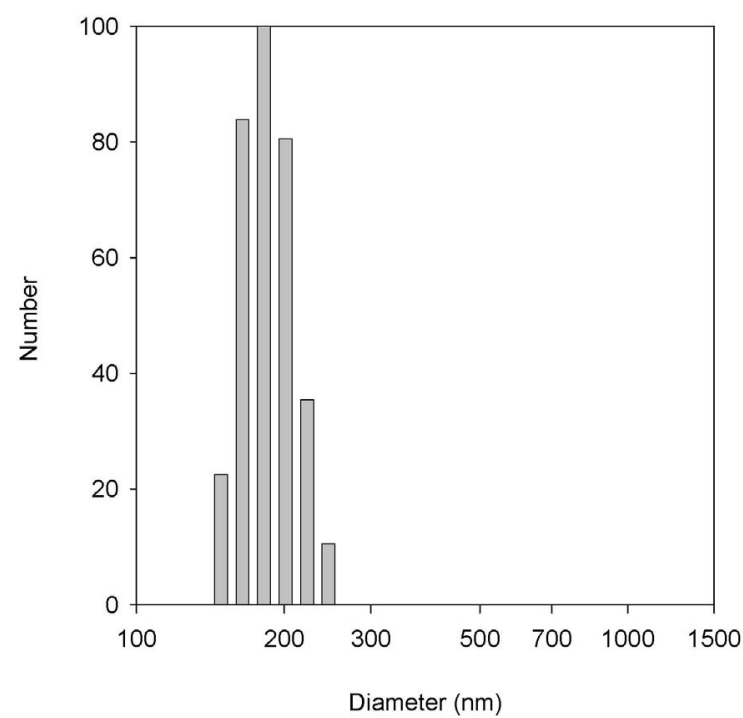

Figure S4. DLS number size distribution of capsules from photochemical polymerization of dibutyl maleate (1) and divinyl PEG 2 showing a monomodal distribution with an average diameter of $186 \pm 23 \mathrm{~nm}$.

(Figure 1, diamonds).

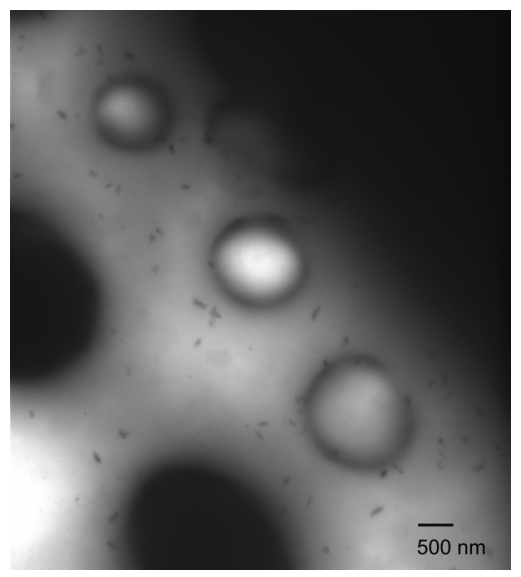

Figure S5. TEM image of larger population of liquid-core capsules ( 1200 nm diameter) that coexist with smaller capsules shown in Figures 2 and S6a-d resulting from thermally initiated polymerization (Figure 1, circles) 

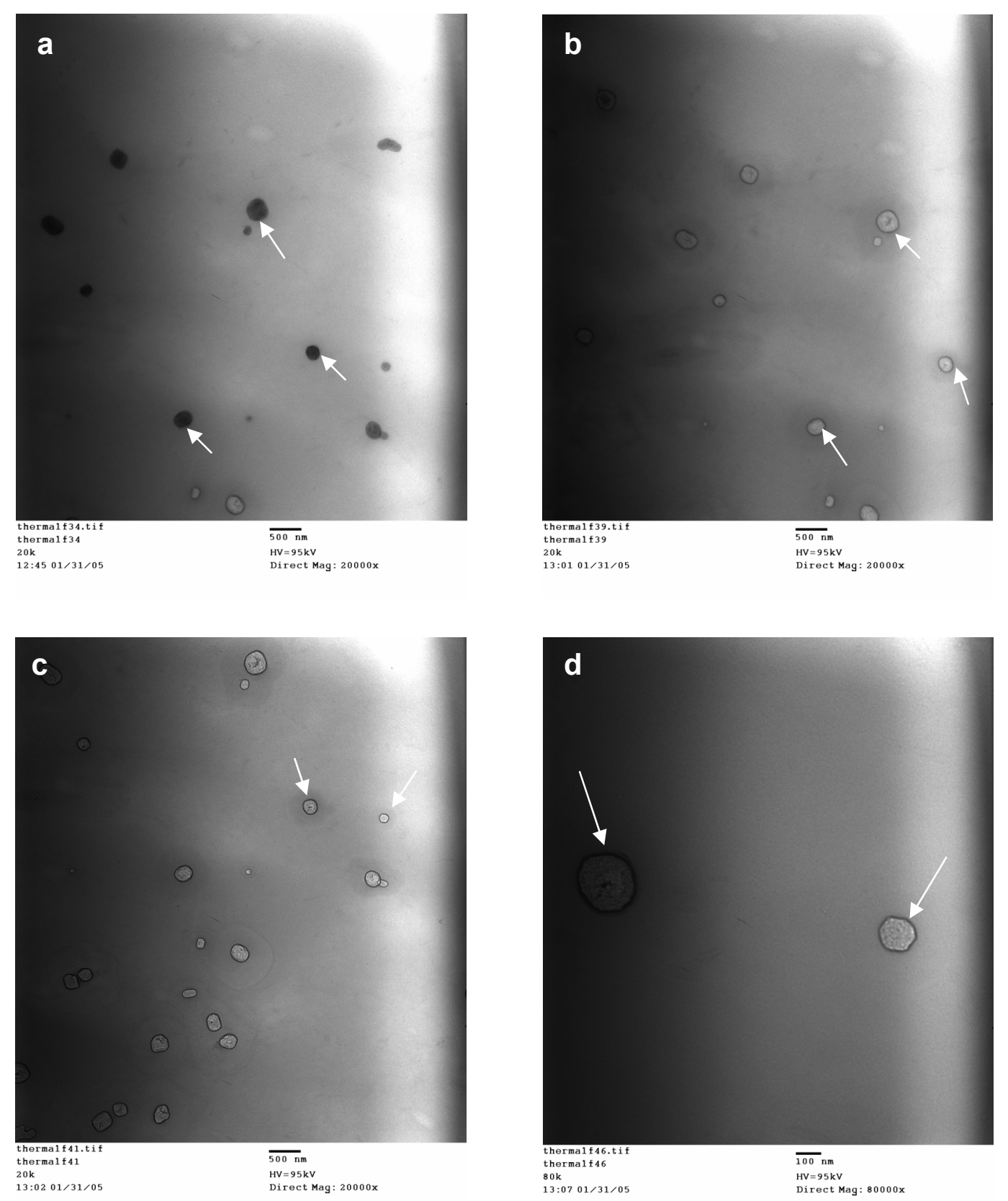

Figure S6. Additional TEM images of liquid core capsules following thermally initiated polymerization (Figure 1, circles). Arrows indicate registration of the images and capsules between images. 

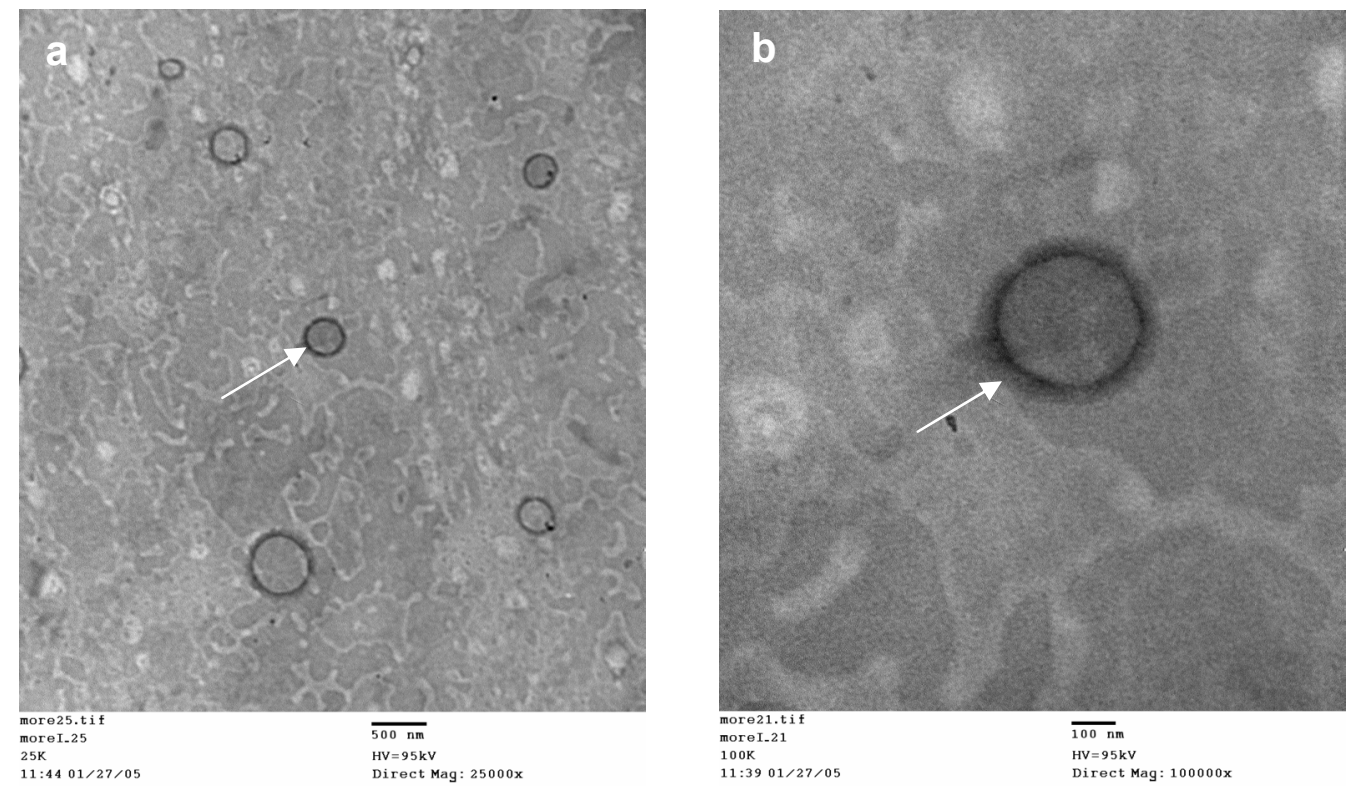

Figure S7. TEM images of liquid core capsules ( $210 \mathrm{~nm}$ diameter) following UV initiated polymerization (Figure 1, diamonds).

\footnotetext{
${ }^{1}$ Sedaghat-Herati, M. R.; Tyndall, M.; Biagioni, R. N. Polym. Bull. 2002, 48, 221-224.

${ }^{2}$ Bizilj, S.; Kelly, D. P.; Serelis, A. K.; Solomon, D. H.; White, K. E. Aust J. Chem. 1985, 38, 1657-1673.
} 